\title{
Intrahepatic Arterioportal Fistula
}

\author{
Satoshi Nakayama
}

Key words: arterioportal fistula, hepatofugal portal blood flow, liver biopsy

(Intern Med 52: 2371, 2013)

(DOI: 10.2169/internalmedicine.52.1166)

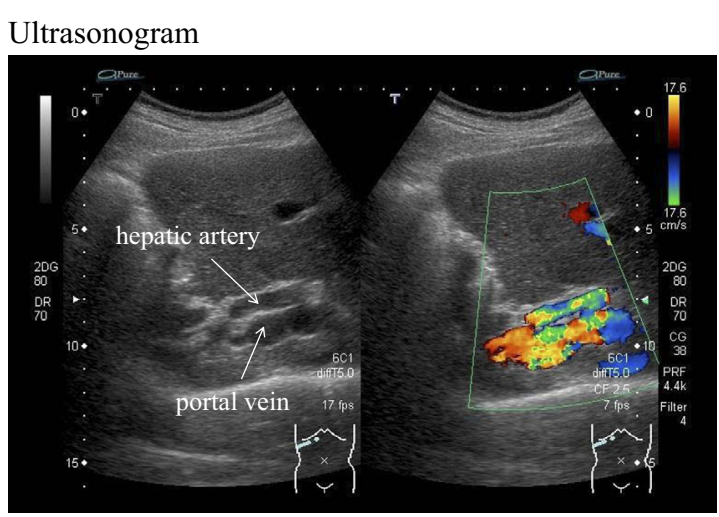

Picture 1.

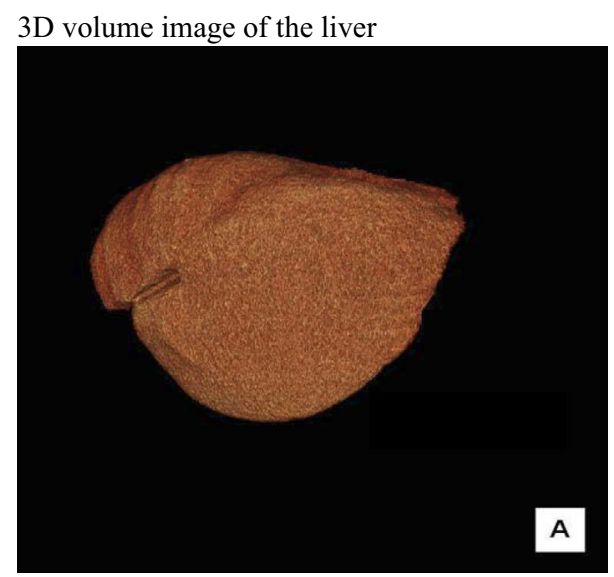

Picture 3.

Intrahepatic arterioportal fistulas infrequently develop in association with hepatic injury or invasive medical procedures $(1,2)$. A 72 -year-old man with type B chronic hepatitis was found to have marked atrophic changes in the right hepatic lobe on ultrasonography. The portal vein and hepatic

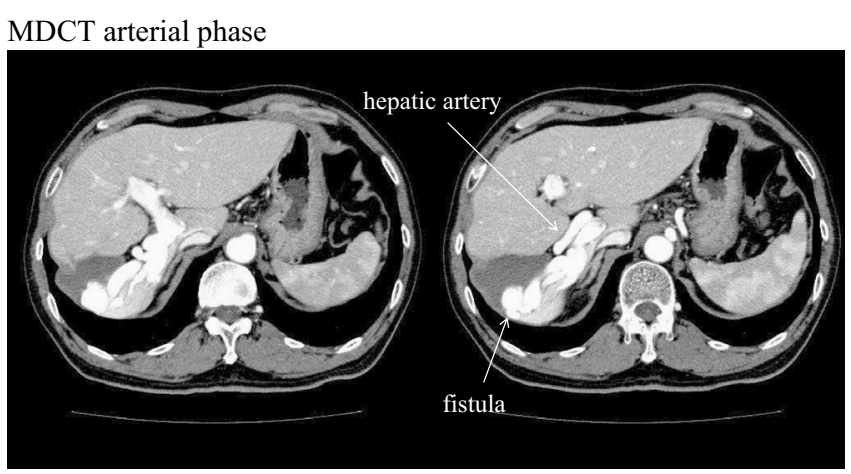

Picture 2.

artery were both dilated in the atrophic right lobe, and the right portal blood flow was hepatofugal (Picture 1). Ultimately, multi-detector row CT (MDCT) revealed an intrahepatic arterioportal fistula in the atrophic right lobe (Picture 2). The bilateral portal branches were enhanced simultaneously in the arterial phase, and an enlarged left lobe was observed on 3D volume images (Picture 3). The patient had undergone a percutaneous liver biopsy of the right lobe at 40 years of age, which was suspected to be causally related to the formation of the fistula. The long-term hepatofugal portal flow into the left lobe via the arterioportal fistula may have contributed to the morphological changes in the liver.

The author states that he has no Conflict of Interest (COI).

\section{References}

1. Guzman EA, McCahill LE, Rogers FB. Arterioportal fistulas: introduction of a novel classification with therapeutic implications. J Gastrointest Surg 10: 543-550, 2006.

2. Iwaki T, Miyatani H, Yoshida Y, et al. Gastric variceal bleeding caused by an intrahepatic arterioportal fistula that formed after liver biopsy: a case report and review of the literature. Clin J Gastroenterol 5: 101-107, 2012.

Department of Gastroenterology, Mishuku Hospital, Japan

Received for publication June 13, 2013; Accepted for publication June 14, 2013

Correspondence to Dr. Satoshi Nakayama, s-nakayama@mishuku.gr.jp

(C) 2013 The Japanese Society of Internal Medicine Journal Website: http://www.naika.or.jp/imonline/index.html 